\title{
Memoria Refugio Pavón
}

\author{
Lorena Troncoso Valencia
}

Reseña

Nombre del Proyecto: Refugio Pavón

Arquitecto: Lorena Troncoso Valencia

Sitio Web: http://www.lorenatroncoso.cl/ E-mail: lorenatroncosov@gmail.com

Ubicación: Las Trancas, Pinto, Chile.

Año construcción: 2016

Superficie construida: $24 \mathrm{~m} 2$

Fotógrafo: Cristóbal Caro

Construcción: Constructora Bocaz, Chillán. Sitio Web: http://www.constructorabocaz.cl/

Recibido: 10 de julio 2017

Aprobado: 13 de julio 2017

\section{Resumen:}

El Refugio Pavón, de la arquitecta Lorena Troncoso Valencia, ubicado en la comuna de Pinto, región de Ñuble de Chile, se emplaza en una pequeña zona sin árboles en medio del bosque, permitiendo un mayor asoleamiento y una vista destacada del refugio con vegetación frondosa a los costados y un gran murallón de piedra natural en el fondo. Predomina el uso de la madera en todo su componente arquitectónico creando espacios de una alta calidez.

Palabras clave: arquitectura chilena; madera, pino radiata; refugio.

\section{Refugio Pavon memorial}

\begin{abstract}
:
Refugio Pavón, by the architect Lorena Troncoso Valencia, located in the municipality of Pinto, region of Ñuble - Chile, is located in a small area without trees in the middle of the forest, allowing a greater sunny and a view of the refuge. It has lush vegetation at the sides and a large wall of natural stone in the background. The use of wood predominates in all its architectural component creating spaces of a high sensation of warmth.
\end{abstract}

Keywords: chilean architecture; wood; radiata pine; refuge 
I refugio se ubica en la comuna de Pinto, región de Ñuble. La localidad cordillerana es reconocida por el turismo en deportes extremos de alta montaña, destacando en su contexto el Volcán Chillán.

El encargo consiste en un pequeño refugio para una joven pareja de escaladores, amantes del deporte en roca. La primera consigna era la restricción de superficie, pero la habilidad física del usuario permitía generar alturas interiores y ampliar el espacio virtualmente. Se consideró dar cabida a las acciones básicas y esenciales para refugiarse, contemplando lo mínimo para dormir, comer e higiene.

Se emplaza en una pequeña zona sin árboles en medio del bosque, permitiendo un mayor asoleamiento y una vista destacada del refugio con vegetación frondosa a los costados y un gran murallón de piedra natural en el fondo.

El refugio se eleva, con pilotes de madera, un metro y medio sobre el terreno natural para evitar contacto con la nieve en temporada de invierno y dar mayor protagonismo en el contexto.

Se plantea la idea de una cáscara (muro y cubierta) que envuelve un frontón retraído, jugando con el lleno de madera y vacío acristalado. Siendo el frontón, la fachada principal, replicando la importancia de la verticalidad del muro de roca que se observa en el fondo del terreno. El quiebre asimétrico de la techumbre permite el escurrimiento de la nieve exteriormente e interiormente dar altura al espacio para dormir, teniendo una capacidad para 4 personas. El espacio interior se organiza en dos niveles; planta baja y altillo, es un espacio abierto, donde el único volumen cerrado es el baño.

La estructura completa es de pino radiata de 2"x3", se destaca el revestimiento interior con el mismo tipo de tabla en piso, cielo y muro. Evitando saturar el espacio y otorgando mayor calidez con el color propio de la madera.

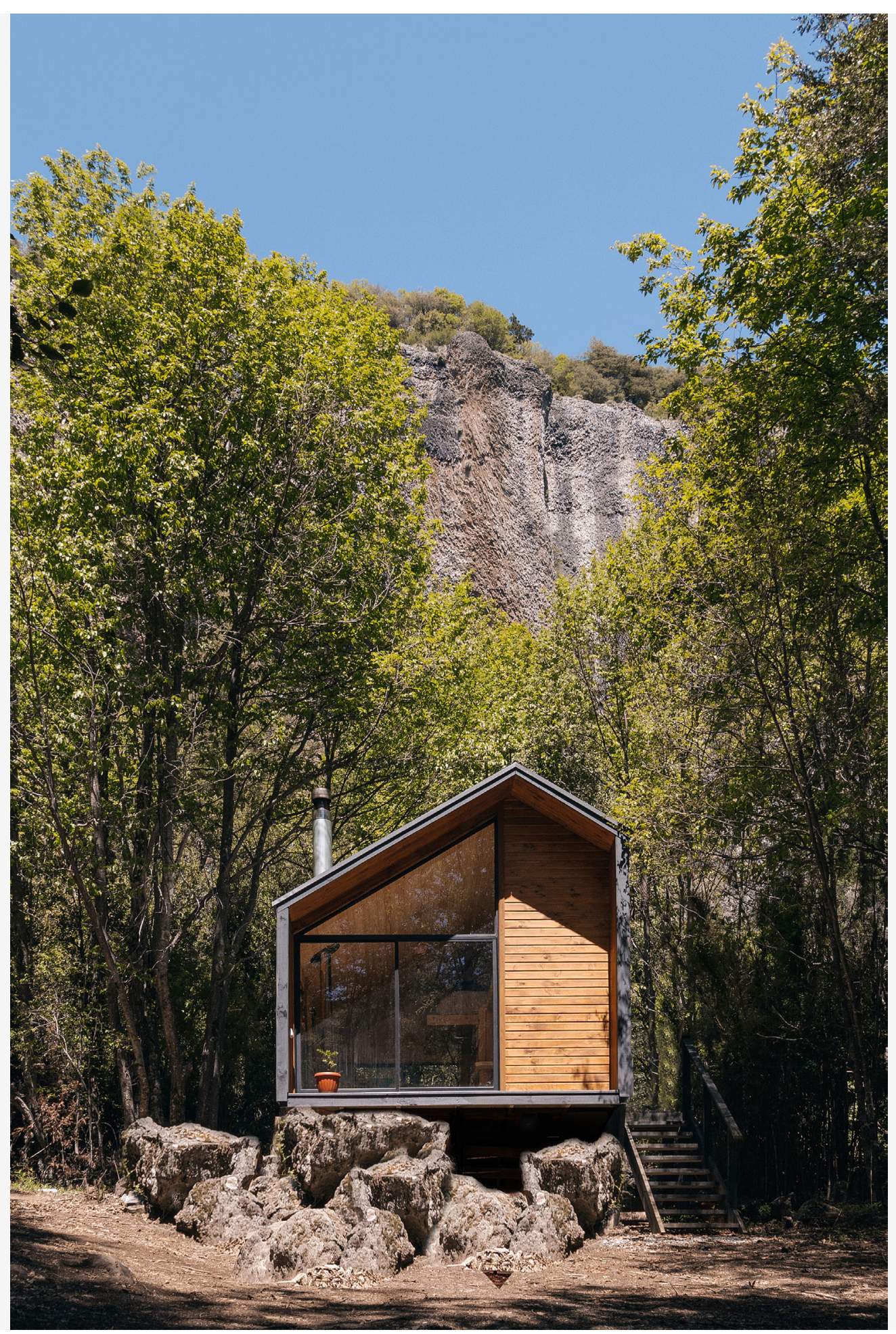




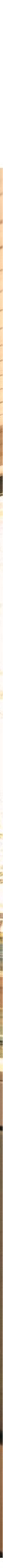

Figura 2. Refugio Pavón

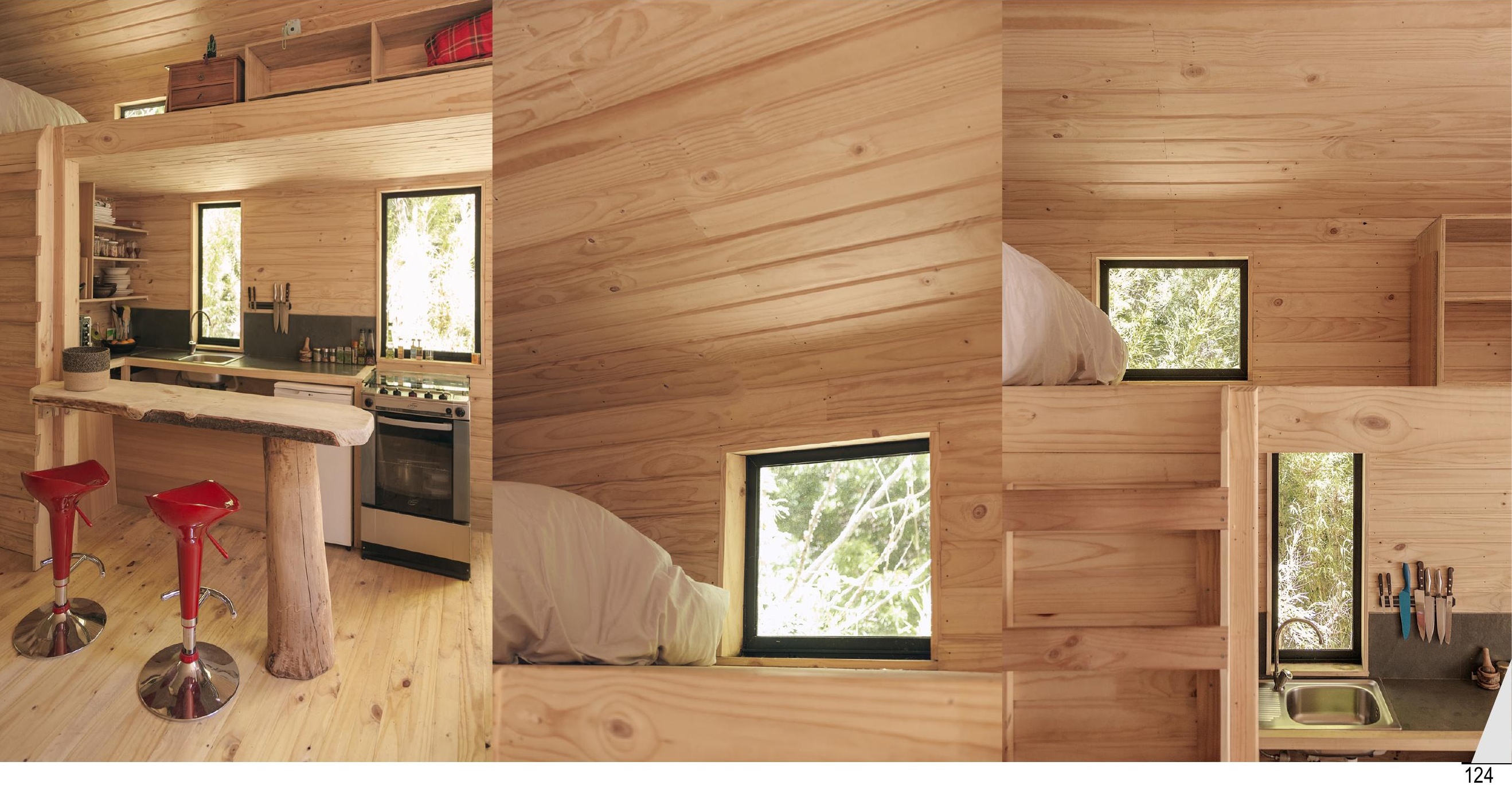

Figura 3-5. Refugio Pavón 

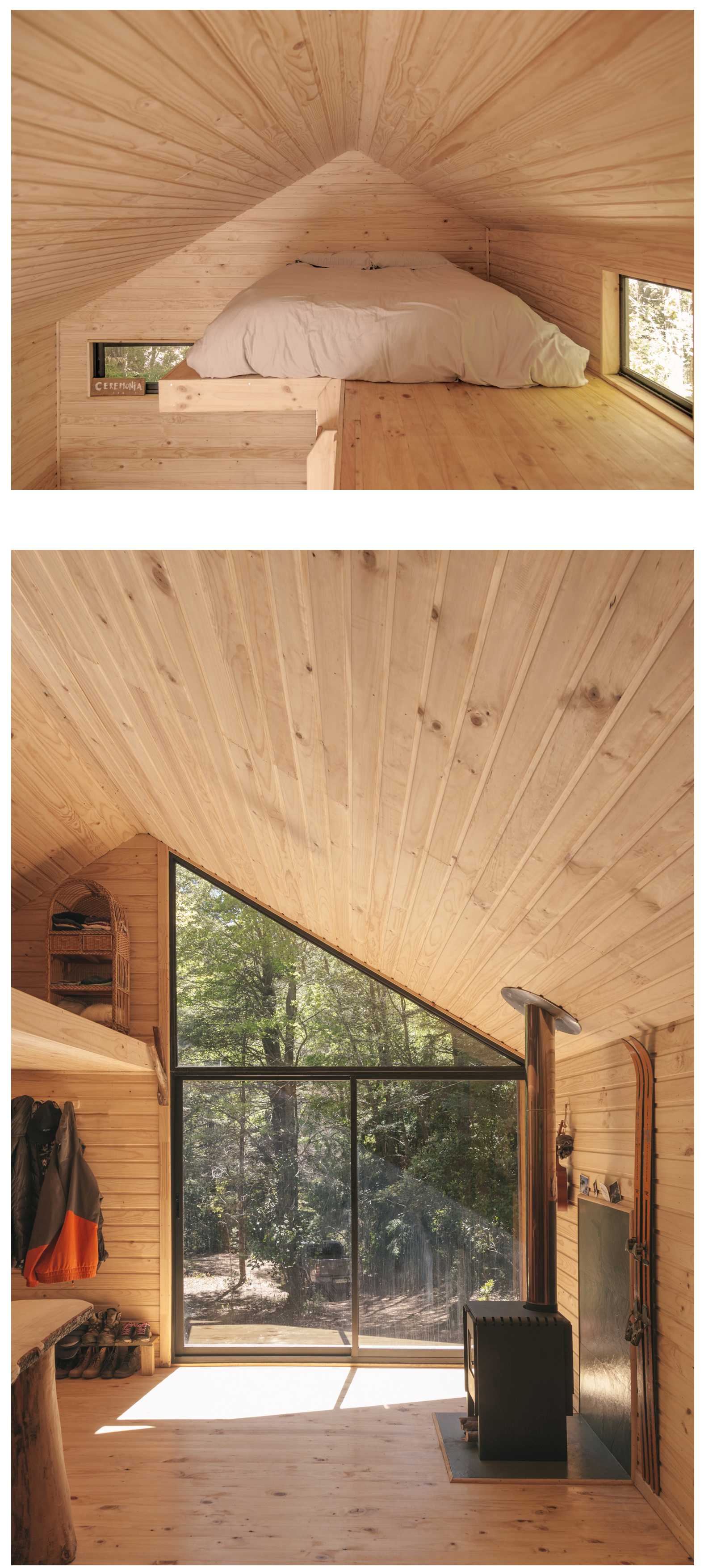